San Jose State University

SJSU ScholarWorks

Faculty Publications

Health Science and Recreation

$1-1-2011$

\title{
The Relations Between Traumatic Exposures, Post-Traumatic Stress Disorder and Anger in Male and Female Veterans
}

Miranda E. Worthen

San Jose State University, miranda.worthen@sjsu.edu

Follow this and additional works at: https://scholarworks.sjsu.edu/healthsci_rec_pub

Part of the Medicine and Health Sciences Commons

\section{Recommended Citation}

Miranda E. Worthen. "The Relations Between Traumatic Exposures, Post-Traumatic Stress Disorder and Anger in Male and Female Veterans" Journal of Feminist Family Therapy (2011): 188-201. https://doi.org/ 10.1080/08952833.2011.604535

This Article is brought to you for free and open access by the Health Science and Recreation at SJSU

ScholarWorks. It has been accepted for inclusion in Faculty Publications by an authorized administrator of SJSU

ScholarWorks. For more information, please contact scholarworks@sjsu.edu. 
The relations between traumatic exposures, post-traumatic stress disorder and anger in male and female Veterans

Miranda Worthen 


\begin{abstract}
Military personnel who have served in Operation Iraqi Freedom (OIF) and Operation Enduring Freedom (OEF) have experienced high rates of combat exposure, which is associated with PTSD. Less is known about the relations between Military Sexual Trauma (sexual harassment, assault, and rape while serving in the military, MST) and PTSD. Little is known about anger problems in this OEF/OIF Veteran population, which research from prior conflicts suggests may be a consequence of both traumas and PTSD. Anger is an emotional state closely related to aggression, hostility, and violence. Veterans who have difficulty controlling anger are at greater risk of interpersonal and employment problems. Uncontrolled anger can lead to aggressive or violent behavior, posing health risks to those around the Veteran and increasingly the likelihood that the Veteran will come into conflict with the law. This article contributes a review of the literature on what little is known about MST and PTSD as well as reviews literature on anger, which may be associated with high combat exposure or MST. Notably, there is almost no research on any of these problems among women Veterans. Given that women make up more than $15 \%$ of deployed service members in Iraq and Afghanistan, research on these relations in women is imperative.
\end{abstract}




\section{Introduction}

During wars in the last century, soldiers were as much as twice as likely to develop psychiatric problems as to sustain physical injuries (Bourke, 1999). Yet research into trauma related psychiatric symptoms among soldiers, currently known as posttraumatic stress disorder (PTSD), has only proliferated recently. While it is now accepted that more stressful combat experiences are associated with PTSD, there are other wartime exposures with potential mental health consequences, such as sexual assault or rape, that are minimally understood.

Although the association between trauma during wartime and anger has been observed since Homer described Achilles' berserk rage in The Iliad, researchers only began to investigate the relationship between trauma and anger recently. One study examined relations between trauma and anger among Vietnam Veterans immediately after the Vietnam war (Yager, 1976), however most research examining the relationship between stressors during war and socio-behavioral outcomes like anger, aggression, hostility and interpersonal violence among Vietnam Veterans developed in the mid-1990s, at least two decades after these individuals had been exposure to war (Chemtob, Hamada et al., 1994).

In extant research examining aspects of trauma, PTSD and anger, few studies have examined the exposures related to PTSD and anger in women soldiers or Veterans, who now make up over $15 \%$ of deployed service members in Iraq and Afghanistan. While studies are beginning to investigate some of these relations in military personnel who 
have served in Operation Iraqi Freedom (OIF), the war in Iraq, and Operation Enduring Freedom (OEF), the war in Afghanistan, most of what we know about these associations come from studies conducted with Veterans from Vietnam; and these studies often took place decades after the war had ended.

This article reviews the literature to date on wartime exposures, PTSD, and sociobehavioral outcomes.

\section{WARTIME EXPOSURES}

\section{Combat Exposure}

Studies define "combat exposure" differently. In older studies with Vietnam Veterans, traumatic exposures during combat were often segmented into participating in or witnessing atrocities, experiencing intense battle where one felt an acute threat of death, and exposure to the aftermath of battle (i.e. caring for the dying or exposure to dead or decomposing bodies) (Beckham, Feldman et al., 1998). Studies with Veterans from the Gulf War to the present have expanded the definition of combat exposures to include more recent threats, such as exposure to or fear of exposure to chemical and biological weapons (Vogt, Pless et al., 2005). While many studies do not use standard scales (Smith, Ryan et al., 2008), standard and non-standard measures currently in use ask subjects about exposure to specific wartime events, with some scales using yes/no item-responses and other scales using a Likert-response format of never to always. 
Studies estimating the prevalence of combat exposure during OEF and OIF are rare. In one recent study of California Veterans, just over half the sample reported exposure to at least one traumatic event during deployment (Baker, Heppner et al., 2009). In a second study of over 40,000 current service members, a similar prevalence was found, with about half of deployed men and slightly fewer than half of deployed women reporting traumatic combat exposures (Wells, LeardMann et al., 2010).

\section{Military Sexual Trauma}

The term Military Sexual Trauma is used by the Veterans Administration (VA) to refer to "severe or threatening forms of sexual harassment and sexual assault sustained in military service" (Kimerling, Gima et al., 2007). The prevalence of MST varies across

populations and across eras of service (Yaeger, Himmelfarb et al., 2006). A large study of OEF and OIF Veterans using VA care reported a prevalence of $15.1 \%$ in women and $0.7 \%$ in men (Kimerling, Street et al., in press). Yet there are reasons to believe that those who experienced MST, particularly women, are less likely to use VA care. Only $40 \%$ of OIF and OEF Veterans use VA care (Seal, 2009). Formative qualitative research has raised concerns that women who experienced MST during deployment do not feel safe at VA facilities and that women suffering from PTSD have been harassed by other Veterans in the waiting room and by providers while seeking care. ${ }^{1}$ Indeed, the few other studies reporting prevalence of MST have found much higher rates. For example, in one study with a sample of female Veterans recruited from a women's health center, researchers reported a prevalence of MST of 41\% (Yaeger, Himmelfarb et al., 2006). Studies among

\footnotetext{
${ }^{1}$ Author conversations with founder of Grace Under Fire and communications director of Swords to Plowshares.
} 
treatment seeking female Veterans have found the prevalence of sexual harassment to be as high as 60\% (Bell, Roth et al., 1998; Fontana and Rosenheck, 1998) and the prevalence of rape to be around 30\% (Sadler, Booth et al., 2000; Sadler, Booth et al., 2005). All of these studies are limited in their inference to treatment seeking populations. No research to date has estimated the prevalence of MST in a population-based, non treatment-seeking sample of Veterans.

\section{RELATIONS BETWEEN EXPOSURES AND TRAUMATIC STRESS Definition and Conceptual Model of Traumatic Stress}

Post-Traumatic Stress Disorder (PTSD) entered the Diagnostic and Statistical Manual in 1980. The adoption of the term came after considerable debate within the psychological and medical community, largely grounded in analyses of the mental health and psychosocial functioning of Vietnam combat Veterans. In the last three decades, PTSD has gained legitimacy both in the United States and internationally. However, there has been a backlash against the "biopsychomedicalization" of a social experience of suffering, especially suffering caused by war (Summerfield, 1999). This debate is not about the biological phenomena of how traumatic stress is metabolized in the body, but rather about what constitutes a legitimate intervention to mitigate such stress, particularly in communities widely impacted by war. While this is an important topic, it is beyond the scope of this article. Rather, I will present current understandings of PTSD, and describe the state of the literature on traumatic stressors during military deployment and PTSD. 
To meet the diagnostic criteria of PTSD, a person must have been exposed to a traumatic event to which he or she responded with fear, helplessness or horror and must have a combination of symptoms in the three symptom clusters of hyperarousal (e.g. the person has difficulty falling asleep or has become more vigilant and concerned about safety), reexperiencing (e.g. the person has intrusive recollections of the event or has intense psychological distress in response to reminders of the traumatic event), and avoidance/numbness (e.g. the person is unable to recall aspects of the event or has a restricted range of emotions or a feeling of numbness) (Yehuda, 2002a; Yehuda, 2002b). Studies have demonstrated altered neurochemical, neuroanotomic, and neuroendocrine responses to stress among those with PTSD (Yehuda, 2002b). For example, daily cortisol levels are lower in many people with PTSD than in people without PTSD. When stressed, people with PTSD demonstrate a more sensitive negative feedback system in the hypothalamic-pituitary-adrenal (HPA) axis, as compared to normal or depressed people. People with PTSD also have increased circulating norepinephrine, have increased reactivity of $\alpha_{2}$-adrenergic receptors, and increased thyroid hormone levels. These alterations result in the somatic symptoms of PTSD, including insomnia, irritability, impaired concentration, hypervigilance, and increased startle response (Yehuda, 2002a).

\section{Combat Exposure and Traumatic Stress}

Exposure to combat during deployment has been associated with higher rates of mental health problems. Several studies conducted with treatment-seeking Vietnam Veterans have demonstrated an association between severity of combat exposure and PTSD (Beckham, Feldman et al., 1997; Beckham, Feldman et al., 1998). Population-based 
studies of Vietnam Veterans and Persian Gulf I Veterans have also described a strong association between severity of combat exposure and PTSD (Fontana, Rosenheck et al., 1997; Sharkansky, King et al., 2000; Kang, Dalager et al., 2005).

Initial research with OIF and OEF Veterans has found an association between combat exposure and PTSD as well (Killgore, Cotting et al., 2008; Smith, Ryan et al., 2008). In the Millennium Cohort, a population-based US military cohort of over 77,000 active and reserve military personnel, symptoms of incident PTSD have been found to be three times more common among deployed personnel who report combat exposures compared to non-deployed personnel (Smith, Ryan et al., 2008).

\section{Military Sexual Trauma and Traumatic Stress}

While most studies of deployment related stressors and PTSD focus on combat exposure, sexual harassment and rape during deployment have also been shown to have a detrimental effect on mental health among Veterans. Recent studies have demonstrated that female military personnel in the Vietnam War suffered rape and harassment during their deployment, however, only of late have researchers focused on this exposure.

In one treatment seeking female population, Suris, Lind et al. (2004) found that Veterans with a history of military sexual assault were nine times more likely to be diagnosed with PTSD compared with those without such history (Suris, Lind et al., 2004). One study of treatment seeking women Veterans reported the association between MST and PTSD in 
women to be four times as large as the association between combat exposure and PTSD in women (Bell, Roth et al., 1998).

A study of non-treatment seeking female Veterans from the Vietnam War also reported a strong association between MST and chronic PTSD (Fontana, Schwartz et al., 1997). Two studies in non-treatment seeking populations from the Persian Gulf War also demonstrated this association. These relations have been described in men as well as women (Kang, Dalager et al., 2005; Vogt, Pless et al., 2005). While Vogt et al. found the association between PTSD and harassment to be stronger among women; they found that harassment was strongly associated with other mental health outcomes (depression and anxiety) for men. Although these relations between MST and depression were also found among women (Street, Stafford et al., 2008), research with US military deployed as peacekeepers in Somalia suggests that the pathways through which harassment and PTSD are associated may be different for men and women (Fontana, Litz et al., 2000).

Initial research on Veterans from OEF/OIF indicates that Veterans who screen positively for MST have significantly increased odds of adjustment disorders, alcohol and substance use disorders, anxiety disorders, depressive disorders, and PTSD (Kimerling, Street et al., in press). This effect is greater than the effect of multiple deployments or long deployments.

In summary, while the research consistently suggests that deployment-related stressors are related to PTSD, the magnitude of the association and the gender differences in the 
effect of combat exposure and exposure to MST on PTSD remain unclear. While there is undoubtedly an association between these stressors and PTSD in current era Veterans, understanding the nuances of these relations will be critical in developing appropriate interventions and for planning purposes as more military personnel demobilize and return to their communities. It is important to understand whether exposure to MST results in different posttraumatic stress symptom clusters than exposure to combat. If there are differences, mental health professionals currently working with Veterans may need training to help them identify these symptoms so that Veterans with PTSD are not misdiagnosed or diagnosed late. Similarly, understanding gender differences in how traumatic stressors during deployment can manifest in posttraumatic stress symptoms will be critical for clinicians as they interview and treat returning Veterans.

The differences in posttraumatic stress symptoms by gender and by traumatic stressor may be particularly apparent with respect to anger, which has been considered both as a symptom of PTSD and as an independently critical mental health problem facing Veterans. Research on anger and its relations to traumatic stressors and PTSD is limited, however, especially among women Veterans. It is to this association that we turn presently.

\section{RELATIONS BETWEEN EXPOSURES, TRAUMATIC STRESS, AND}

ANGER

\section{Definition of Anger}


There are many ways of conceptualizing anger. The present literature review is grounded in Chemtob et al.'s (Chemtob, Novaco et al., 1997) model of anger and the relationship between anger and traumatic stress. This model was developed through work with Vietnam Veterans and is thus most relevant to the population being considered.

Chemtob et al. describe anger as "an emotional state that has both adaptive and maladaptive effects on behavior" (p. 18). They draw on Novaco's model of anger, which concentrates attention on three domains of anger: cognitive processing of environmental circumstances, physiological arousal, and behavioral reactions. These three domains are reciprocally related. In people with combat-related trauma, anger can become intrusive and is part of a broader "dyscontrol syndrome associated with heightened arousal, hostile appraisal, and antagonistic behavior in response to severe threat" (p. 22). Chemtob et al. present a conceptual model that relates anger regulation structures to threat structures, which are activated in what they term "survival mode," in people suffering from traumatic stress (see Figure 1). 
Miranda Worthen

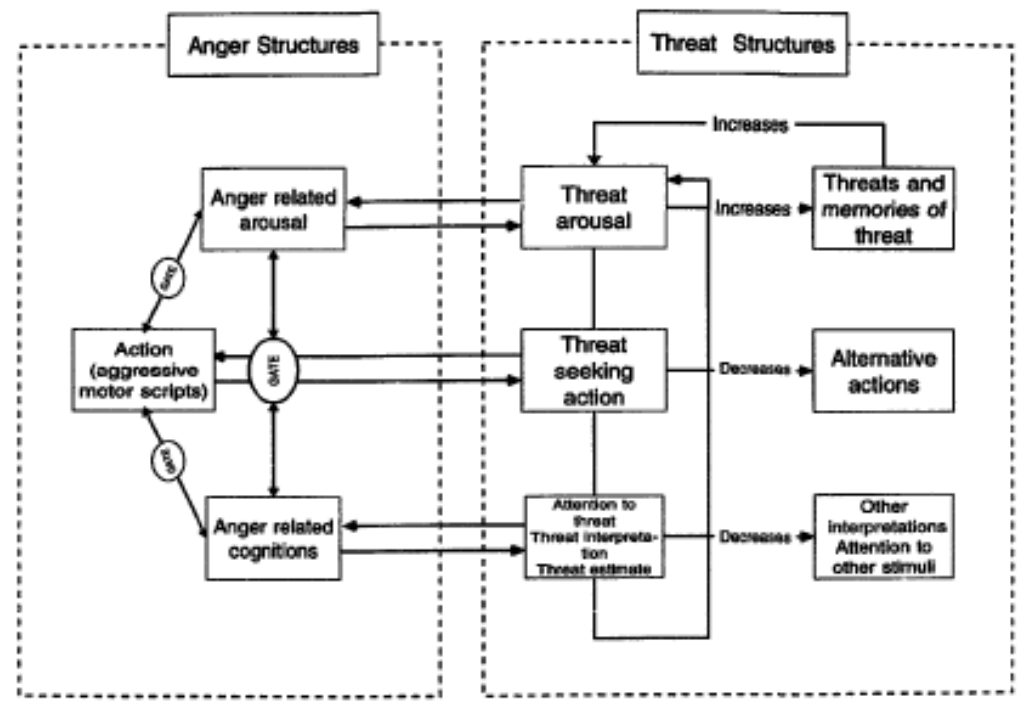

Figure 1: Chemtob et al. (1997) Regulatory Model of Posttraumatic Anger (p. 31).

The three anger domains in Figure 1 typically interact to depress or inhibit an anger response when it is not appropriate. For example, a person who feels aroused may begin a cognitive process that produces the thought that an angry outburst would only exacerbate a situation and so the cognition works to inhibit the action. This inhibitory function is represented by the gates between each domain. According to this conceptual model, however, in people with PTSD, the typical pattern of inter-regulation between domains is affected by the traumatic experience, leading to a rapid escalation of threat perception, such that inhibitions, symbolized by the gates, are overridden, and the perception of threat transforms to anger rapidly and results in "near automatic action" (30).

Anger dysregulation leads to greater interpersonal conflict, as a person's cognitive process more rapidly perceives threat and anger and leads to heighted arousal. In addition the rapid escalation of cognition to action makes dysregulated anger a particular public health concern as it often results in aggressive or violent behavior. 


\section{Traumatic Stress and Anger}

While an association has been described between PTSD symptoms and anger and aggression in several studies of male, treatment-seeking Vietnam Veterans (Chemtob, Hamada et al., 1994; McFall, Wright et al., 1999; Crawford, Calhoun et al., 2007; Taft, Kaloupek et al., 2007; Taft, Vogt et al., 2007), concerns about the universality of results from these samples persist. One study, for example, measured the association only among Veterans in treatment for substance abuse (McFall, Wright et al., 1999). Another used data from self-report on aggression problems among Veterans applying for disability benefits for PTSD (Taft, Vogt et al., 2007).

Only four studies were found that examined these relations among non-Vietnam populations: one study of World War II former prisoners of war (O'Donnell, Cook et al., 2006); one qualitative study examining ten Canadian peacekeepers (Ray and Vanstone, 2009); one study of 90 treatment seeking women Veterans from all eras (Butterfield, Forneris et al., 2000); and one study of 117 treatment-seeking Veterans from OIF/OEF receiving care at the Puget Sound Veterans Administration hospital (Jakupcak, Conybeare et al., 2007). While these four studies use different methods and examined disparate outcomes, they all found that greater levels of PTSD symptoms were associated with heightened levels of anger, aggression, and interpersonal conflicts.

While the studies with Vietnam Veterans were conducted decades after the traumatic exposure, several studies by Taft et al. have shed light on the nuances of the relations 
between anger and PTSD in this particular population. In a study of 60 male Vietnam Veterans, exposure to stimuli reminiscent of battle produced greater physiologic responses in those with PTSD compared to those without PTSD (Taft, Street et al., 2007). Those with PTSD demonstrated higher state and trait anger levels and heightened anger reactivity compared to those without PTSD. In a second study, Taft, Vogt et al. found that the cluster of dysphoric symptoms associated with PTSD and depression were most strongly associated with aggression (Taft, Vogt et al., 2007). In a third study of 1328 male Vietnam Veterans, Taft, Kaloupek et al. reported that only hyperarousal symptoms of PTSD were associated with increased aggression; avoidance and numbing symptoms of PTSD were associated with decreased aggression (Taft, Kaloupek et al., 2007).

Only one study has examined the relationship between PTSD and socio-behavioral outcomes among women (Butterfield, Forneris et al., 2000). This study of 90 treatmentseeking women found a similar association between PTSD and anger, aggression, and hostility among women as has been reported in the male populations. A literature review by Beckham, Calhoun et al. examined the literature on the relationship between PTSD, hostility, and general health functioning in women and reported that few studies had examined the relations between PTSD and anger, aggression or hostility in any female population (Beckham, Calhoun et al., 2002).

\section{Deployment Trauma Exposures, Traumatic Stress, and Anger}

Research examining the association between deployment-related exposures, war-related PTSD and socio-behavioral outcomes like anger, aggression, hostility and interpersonal 
violence is scant. Findings conflict about whether there is a direct association between combat exposure and socio-behavioral outcomes, or whether this association is entirely mediated by PTSD.

Three studies of male, treatment-seeking Vietnam Veterans found that combat exposure is only associated with anger or aggression through PTSD (Lasko, Gurvits et al., 1994; McFall, Wright et al., 1999; Taft, Vogt et al., 2007). Similarly, two studies with male, treatment-seeking Vietnam Veterans showed an association between combat exposure and intimate partner violence only through PTSD (Gondolf and Foster, 1991; Beckham, Feldman et al., 1998). However, three other studies with similar populations have described a direct association between combat exposure and violent behavior apart from any association mediated through PTSD (Hiley-Young, Blake et al., 1995; Beckham, Feldman et al., 1997; Orcutt, King et al., 2003). No studies have examined other deployment-related exposures, such as MST, and socio-behavioral problems.

\section{LIMITATIONS OF CURRENT RESEARCH}

There are several limitations to the research that has been conducted to date. Many of the studies evaluating wartime exposure have measured the exposure many years after the exposure happened, suggesting possible recall bias, with those experiencing current distress more likely to remember adverse circumstances during deployment, and a high likelihood of generally inaccurate recall. In addition, the long time lag between the wartime exposures and the assessment of outcomes of interest (PTSD or socio-behavioral problems) mean important unmeasured factors, like coping strategies or social support, 
could be mediating or modifying this relationship in ways that have not been considered. While more is known about combat exposures, little to nothing is known about the longer term effects of MST. It is also unknown whether the associations described between PTSD and socio-behavioral outcomes are actually only a result of chronic PTSD experienced over many decades or whether the association might also be observable in a population with newly incident PTSD.

The particular samples that have been most studied also limit the generalizability of the findings. Most studies have only examined male, treatment-seeking populations of Vietnam Veterans. The associations in the general Veteran population may be quite different. Very few studies have included women and even those studies that do include women, rarely present separate analyses for women. For example, in a study of anger, hostility, PTSD and overall health, while women made up a remarkable $61 \%$ of the sample, no analysis is presented in the article comparing the results by gender and the issue of effect modification by gender was not addressed (Ouimette, Cronkite et al., 2004).

\section{SUGGESTIONS FOR FUTURE RESEARCH}

Important questions remain concerning the relations between wartime stressors, mental health problems and socio-behavioral outcomes. Research is needed that evaluates these relations among a population-based sample of recently returned Veterans from Operation Enduring Freedom and Operation Iraqi Freedom, including both men and women. 
Such a study should begin with investigating the relations between stressors during deployment and post-traumatic stress disorder (PTSD). Although this association has been found in previous era populations, the magnitude of this relationship in a general sample of current era Veterans is unknown. Given prior research, we could expect to find the following results: 1) Increased exposure to military sexual trauma (MST) will be positively associated with PTSD; 2) Increased exposure to combat will be positively associated with PTSD; 3) The associations observed above will be different by gender. In addition, exposure to trauma prior to service in the military may make one less resilient to traumatic stressors during military service and so we could expect: 4) The effect of deployment related traumatic stressors on the development of PTSD will be different in populations exposed to prior trauma compared with the effect in populations without prior trauma.

The study would go on to evaluate the relations between post-deployment PTSD and anger. Given previous research, we might expect to find the following results: 1) Subjects with PTSD will have a higher level of anger than subjects without PTSD; 2) An increased burden of total PTSD symptoms, regardless of whether a subject is classified as PTSD positive or negative, will be associated with increased level of anger; 3) The association between PTSD and anger will be different by gender.

Subsequent analyses should investigate whether the association between PTSD and anger differs depending on the traumatic exposure that triggered the PTSD. One could hypothesize that the association between PTSD and anger will be different among those 
who developed PTSD after exposure to MST and those who developed PTSD after traumatic combat exposure. Another subsequent analysis would be to evaluate whether there may be different pathological trajectories that lead subjects to experience or avoid explosive anger. For example, some Veterans with PTSD may use extreme numbing to avoid explosive anger. Numbing in this manner could have its own psychosocial sequelae and would thus be important to investigate.

This research would have policy implications as well as clinical benefits. For example, current military policy is to discharge dishonorably personnel who get into violent altercations. If a link could be established between a military-related traumatic exposure, symptoms of PTSD, and anger problems leading to violent behavior, Veterans discharged dishonorably may be able to appeal for a medical discharge instead, allowing them to be eligible for Veterans benefits, including access to the Veterans Health Administration benefits.

Clinical implications are also apparent. If mental health professionals working within and outside the VA system had a better understanding of the relations between traumatic experiences, PTSD symptoms, and anger problems, then more targeted therapy could be used with effected Veterans. For example, anger management training could be integrated with cognitive behavioral therapy and other trauma therapies, even for those patients currently not exhibiting anger problems. 
Crucially, appropriate support services could be made available to Veteran's families struggling to support returning Veterans experiencing anger management problems. While families report benefits from programs designed to prepare families of returning personnel about PTSD symptoms, initial qualitative research suggests that when Veterans become angry, relationships with family members are often the first to fray. This not only creates negative consequences for a family like divorce, substance use, and family violence, but also often results in depriving the Veteran of a critical supportive resource to help him or her through reintegration. Programs designed to increase awareness among families of the relations between trauma and anger could enable them to better care for their returning Veteran and feel less bewildered by what they may view as a personality shift. Families could also be enlisted to help Veterans seek professional care for anger management problems, recognizing that they may be part of a larger mental health burden.

More knowledge about the relations between traumatic exposures, symptoms of PTSD, and anger management problems would benefit clinicians hoping to prevent early anger management problems from becoming obstacles to maintaining good relationships with family and friends and becoming a barrier to employment. With greater knowledge about these relations, more appropriate interventions could be designed to support Veterans and their families.

\section{Works Cited}


Baker, D. G., Heppner, P., Afari, N., Nunnink, S., Kilmer, M., Simmons, A., et al. (2009). Trauma exposure, branch of service, and physical injury in relation to mental health among U.S. veterans returning from Iraq and Afghanistan. Mil Med, 174(8), 773778.

Beckham, J. C., Calhoun, P. S., Glenn, D. M., \& Barefoot, J. C. (2002). Posttraumatic stress disorder, hostility, and health in women: a review of current research. Ann Behav Med, 24(3), 219-228.

Beckham, J. C., Feldman, M. E., \& Kirby, A. C. (1998). Atrocities exposure in Vietnam combat veterans with chronic posttraumatic stress disorder: relationship to combat exposure, symptom severity, guilt, and interpersonal violence. J Trauma Stress, 11(4), $777-785$.

Beckham, J. C., Feldman, M. E., Kirby, A. C., Hertzberg, M. A., \& Moore, S. D. (1997). Interpersonal violence and its correlates in Vietnam veterans with chronic posttraumatic stress disorder. J Clin Psychol, 53(8), 859-869.

Bell, E. A., Roth, M. A., \& Weed, G. (1998). Wartime stressors and health outcomes: women in the Persian Gulf War. J Psychosoc Nurs Ment Health Serv, 36(8), 19-25.

Bourke, J. (1999). An Intimate History of Killing. London: Granta Books. 
Butterfield, M. I., Forneris, C. A., Feldman, M. E., \& Beckham, J. C. (2000). Hostility and functional health status in women veterans with and without posttraumatic stress disorder: a preliminary study. J Trauma Stress, 13(4), 735-741.

Chemtob, C. M., Hamada, R. S., Roitblat, H. L., \& Muraoka, M. Y. (1994). Anger, impulsivity, and anger control in combat-related posttraumatic stress disorder. J Consult Clin Psychol, 62(4), 827-832.

Chemtob, C. M., Novaco, R. W., Hamada, R. S., Gross, D. M., \& Smith, G. (1997). Anger regulation deficits in combat-related posttraumatic stress disorder. J Trauma Stress, 10(1), 17-36.

Crawford, E. F., Calhoun, P. S., Braxton, L. E., \& Beckham, J. C. (2007). Validity of the Personality Assessment Inventory Aggression scales and Violence Potential index in veterans with PTSD. J Pers Assess, 88(1), 90-98.

Fontana, A., Litz, B., \& Rosenheck, R. (2000). Impact of combat and sexual harassment on the severity of posttraumatic stress disorder among men and women peacekeepers in Somalia. J Nerv Ment Dis, 188(3), 163-169.

Fontana, A., \& Rosenheck, R. (1998). Duty-related and sexual stress in the etiology of PTSD among women veterans who seek treatment. Psychiatr Serv, 49(5), 658-662. 
Fontana, A., Rosenheck, R., \& Horvath, T. (1997). Social support and psychopathology in the war zone. J Nerv Ment Dis, 185(11), 675-681.

Fontana, A., Schwartz, L. S., \& Rosenheck, R. (1997). Posttraumatic stress disorder among female Vietnam veterans: a causal model of etiology. Am J Public Health, 87(2), $169-175$.

Gondolf, E. W., \& Foster, R. A. (1991). Wife assault among VA alcohol rehabilitation patients. Hosp Community Psychiatry, 42(1), 74-79.

Hiley-Young, B., Blake, D. D., Abueg, F. R., Rozynko, V., \& Gusman, F. D. (1995). Warzone violence in Vietnam: an examination of premilitary, military, and postmilitary factors in PTSD in-patients. J Trauma Stress, 8(1), 125-141.

Jakupcak, M., Conybeare, D., Phelps, L., Hunt, S., Holmes, H. A., Felker, B., et al. (2007). Anger, hostility, and aggression among Iraq and Afghanistan War veterans reporting PTSD and subthreshold PTSD. J Trauma Stress, 20(6), 945-954.

Kang, H., Dalager, N., Mahan, C., \& Ishii, E. (2005). The role of sexual assault on the risk of PTSD among Gulf War veterans. Ann Epidemiol, 15(3), 191-195.

Killgore, W. D., Cotting, D. I., Thomas, J. L., Cox, A. L., McGurk, D., Vo, A. H., et al. (2008). Post-combat invincibility: violent combat experiences are associated with 
increased risk-taking propensity following deployment. J Psychiatr Res, 42(13), 11121121.

Kimerling, R., Street, A., Pavao, J., Smith, M., Cronkite, R., Holmes, T., et al. (in press). Military-Related Sexual Trauma among VHA Patients Returning from Iraq and Afghanistan.

Kimerling, R. E., Gima, K., Smith, M. W., Street, A. E., \& Frayne, S. M. (2007). The Veterans Health Administration and Military Sexual Trauma. American Journal of Public Health, 97(12), 2160 - 2166.

Lasko, N. B., Gurvits, T. V., Kuhne, A. A., Orr, S. P., \& Pitman, R. K. (1994). Aggression and its correlates in Vietnam veterans with and without chronic posttraumatic stress disorder. Compr Psychiatry, 35(5), 373-381.

McFall, M. E., Wright, P. W., Donovan, D. M., \& Raskind, M. (1999). Multidimensional assessment of anger in Vietnam veterans with posttraumatic stress disorder. Compr Psychiatry, 40(3), 216-220.

Novaco, R. W., \& Chemtob, C. M. (2002). Anger and combat-related posttraumatic stress disorder. J Trauma Stress, 15(2), 123-132. 
O'Donnell, C., Cook, J. M., Thompson, R., Riley, K., \& Neria, Y. (2006). Verbal and physical aggression in World War II former prisoners of war: role of posttraumatic stress disorder and depression. J Trauma Stress, 19(6), 859-866.

Orcutt, H. K., King, L. A., \& King, D. W. (2003). Male-perpetrated violence among Vietnam veteran couples: relationships with veteran's early life characteristics, trauma history, and PTSD symptomatology. J Trauma Stress, 16(4), 381-390.

Ouimette, P., Cronkite, R., Henson, B. R., Prins, A., Gima, K., \& Moos, R. H. (2004). Posttraumatic stress disorder and health status among female and male medical patients. J Trauma Stress, 17(1), 1-9.

Ray, S. L., \& Vanstone, M. (2009). The impact of PTSD on veterans' family relationships: an interpretative phenomenological inquiry. Int J Nurs Stud, 46(6), 838847.

Sadler, A. G., Booth, B. M., \& Doebbeling, B. N. (2005). Gang and multiple rapes during military service: health consequences and health care. J Am Med Womens Assoc, 60(1), $33-41$.

Sadler, A. G., Booth, B. M., Nielson, D., \& Doebbeling, B. N. (2000). Health-related consequences of physical and sexual violence: women in the military. Obstet Gynecol, 96(3), 473-480. 
Sharkansky, E. J., King, D. W., King, L. A., Wolfe, J., Erickson, D. J., \& Stokes, L. R. (2000). Coping with Gulf War combat stress: mediating and moderating effects. J Abnorm Psychol, 109(2), 188-197.

Sinisi, S. E., \& Laan, M. J. v. d. (2004). Loss-Based Cross-Validated Deletion/Substitution/Addition Algorithms in Estimation. U.C. Berkeley Division of Biostatistics Working Paper Series, 143.

Smith, T. C., Ryan, M. A., Wingard, D. L., Slymen, D. J., Sallis, J. F., \& KritzSilverstein, D. (2008). New onset and persistent symptoms of post-traumatic stress disorder self reported after deployment and combat exposures: prospective population based US military cohort study. BMJ, 336(7640), 366-371.

Street, A. E., Stafford, J., Mahan, C. M., \& Hendricks, A. (2008). Sexual harassment and assault experienced by reservists during military service: prevalence and health correlates. J Rehabil Res Dev, 45(3), 409-419.

Summerfield, D. (1999). A critique of seven assumptions behind psychological trauma programmes in war-affected areas. Soc Sci Med, 48(10), 1449-1462. 
Suris, A., Lind, L., Kashner, T. M., Borman, P. D., \& Petty, F. (2004). Sexual assault in women veterans: an examination of PTSD risk, health care utilization, and cost of care. Psychosom Med, 66(5), 749-756.

Taft, C. T., Kaloupek, D. G., Schumm, J. A., Marshall, A. D., Panuzio, J., King, D. W., et al. (2007). Posttraumatic stress disorder symptoms, physiological reactivity, alcohol problems, and aggression among military veterans. J Abnorm Psychol, 116(3), 498-507.

Taft, C. T., Street, A. E., Marshall, A. D., Dowdall, D. J., \& Riggs, D. S. (2007). Posttraumatic stress disorder, anger, and partner abuse among Vietnam combat veterans. J Fam Psychol, 21(2), 270-277.

Taft, C. T., Vogt, D. S., Marshall, A. D., Panuzio, J., \& Niles, B. L. (2007). Aggression among combat veterans: relationships with combat exposure and symptoms of posttraumatic stress disorder, dysphoria, and anxiety. J Trauma Stress, 20(2), 135-145.

Vogt, D. S., Pless, A. P., King, L. A., \& King, D. W. (2005). Deployment stressors, gender, and mental health outcomes among Gulf War I veterans. J Trauma Stress, 18(3), 272-284.

Wells, T. S., LeardMann, C. A., Fortuna, S. O., Smith, B., Smith, T. C., Ryan, M. A., et al. (2010). A prospective study of depression following combat deployment in support of the wars in Iraq and Afghanistan. Am J Public Health, 100(1), 90-99. 
Miranda Worthen

Yaeger, D., Himmelfarb, N., Cammack, A., \& Mintz, J. (2006). DSM-IV diagnosed posttraumatic stress disorder in women veterans with and without military sexual trauma. Journal of General Internal Medicine. Special Issue: Improving health care for women veterans, 21(Suppl 3), S65-S69.

Yager, J. (1976). Postcombat violent behavior in psychiatrically maladjusting soldiers. Arch Gen Psychiatry, 33(11), 1332-1335.

Yehuda, R. (2002a). Clinical relevance of biologic findings in PTSD. Psychiatr Q, 73(2), 123-133.

Yehuda, R. (2002b). Post-traumatic stress disorder. N Engl J Med, 346(2), 108-114. 